Military Technical College

Kobry El-Kobbah, Cairo, Egypt

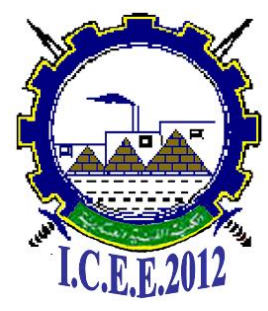

$6^{\text {th }}$ International Conference on

Chemical \& Environmental Engineering

29 -31 May, 2012.

\title{
CPTB-1
}

\section{PREPARATION OF SILVER NANOPARTICLES BY CHEMICAL REDUCTION METHOD AND ITS CHARACTERIZATION AND APPLICATION AS ANTIBACTERIAL AGENT}

\author{
Wafaa I.A*,Fayed M.S ${ }^{* *}$, Gobara M.M , Mostafa S.F**
}

\begin{abstract}
Silver nano particles were prepared by reducing silver nitrate in an aqueous solution with sodium citrate and sodium borohydride. The formation of the silver nano particles was determined using UV-Vis absorption spectroscopy. The energy-dispersive spectroscopy (EDX) of the nano particles dispersion confirmed the presence of elemental silver signal where no peaks of other impurities were detected. The average size of silver nano-particles was determined by transmission electron microscopy (TEM). The synthesized nano particles have been structurally characterized by X-ray diffraction (XRD). Additionally, the antibacterial activity of the nano particle dispersion was measured by standard surface plating-count method. The prepared silver nano particles showed high antimicrobial activity against gram positive Escherichia Coli bacteria (E.Coli).
\end{abstract}

\section{Key Words}

Silver nano particles, silver nitrate, sodium citrate, sodium borohydride, antibacterial property, Escherichia Coli.

\footnotetext{
* The National Research Centre.

** Egytian Armed Forces
} 


\section{Introduction}

Catalysis with silver nano particles has received special attention recently due to the efficiency demonstrated by these systems in developing new catalysts for a wide variety of reactions [1].In recent years noble metal nano particles have been the subjects of focused researches due to their unique electronic, optical, mechanical, magnetic and chemical properties that are significantly different from those of bulk materials [2].

These special and unique properties could be attributed to their small sizes and large specific surface area. For these reasons metallic nano particles have found uses in many applications in deferent fields as medicine, catalysis, electronics, and photonics [3].A variety of preparation routes have been reported for the preparation of metallic nano particles [4].

In recent years nano particles of silver have been found to exhibit interesting antibacterial activities [5]. Presently, the investigation of this phenomenon has regained importance due to the increase of bacterial resistance to antibiotics, caused by their overuse. Recently, silver nano particles exhibiting antimicrobial activity have been synthesized [6]. The use of silver nano particles as antibacterial agent is relatively new. Because of their high reactivity due to the large surface to volume ratio, nano particles play a crucial role in inhibiting bacterial growth in aqueous and solid media. Silver containing materials can be employed to eliminate microorganisms on textile fabrics or they can be used for water treatment [7].

Contrary to bactericide effects of ionic silver, the antimicrobial activity of colloid silver particles are influenced by the dimensions of the particles the smaller the particles, the greater antimicrobial effect [8]. Silver nano particles have been produced using different methods, the simplest and the most commonly used bulk-solution synthetic method for metal nano particles is the chemical reduction of metal salts [9]. In fact, production of nano sized metal silver particles with different morphologies and sizes using chemical reduction of silver salts has been reported. This synthetic method involves reduction of an ionic salt in an appropriate medium in the presence of surfactant using various reducing agents [10].

The antibacterial characteristics of silver nano particles produced have been demonstrating by directly exposing bacteria to colloid silver particles solution [11]. The antimicrobial susceptibility of silver nano particles was evaluated using the antibacterial activity of Ag nano particles for inactivating E. coli O157:H7 (E. coli). The bacteria concentration was determined by the standard surface plating-count method [12].In the present work silver nano particles were prepared by reducing AgNO3 in an aqueous solution using sodium citrate which added to AgNO3 aqueous solution in an ice bath, then $\mathrm{NaBH} 4$ was added to the solution at once with strong stirring and a black powder formed in solution. The prepared silver was evaluated as antibacterial material; it was tested in agar media containing E. coli bacteria.

\section{Experimental Work}

\subsection{Materials and preparation method}

Silver colloids were prepared by reducing $\mathrm{AgNO}_{3}$ in an aqueous solution. In a typical preparation, $0.294 \mathrm{~g}$ sodium citrate was added to $50 \mathrm{~cm}^{3}$ of $10 \mathrm{mM} \mathrm{AgNO}$ aqueous solution in an ice bath. $\mathrm{NaBH}_{4}(0.019 \mathrm{~g})$ was added to the solution at once with strong stirring and a black powder formed in solution. The solution was then filtered and dried at room temperature under vacuum. All chemicals and reagents used in this study are in fine grade. 


\subsection{Characterization techniques}

Ultraviolet-visible Spectroscopy (UV-Vis) revealing the formation of the silver nano particles by exhibing the typical surface plasmon absorption maxima at $382-386 \mathrm{~nm}$ from the $\mathrm{UV}-\mathrm{V}$ is spectrum. The studies of size, morphology and composition of the nano particles were performed by means of transmission electron microscopy (TEM) and energy dispersive X-ray Analysis (EDX). TEM photographs indicate that the nano powders consist of well dispersed agglomerates of grains with a narrow size distribution $(20$ and $80 \mathrm{~nm})$, whereas the radius of the individual particles are between 20 and $40 \mathrm{~nm}$. The X-ray diffraction (XRD) characterize the structure of the synthesized nano particles. The peaks in the XRD pattern are in good agreement with the standard values of the face-centered-cubic form of metallic silver and no peaks of other impurity crystalline phases were detected.

\subsection{Measurements of the antibacterial activity}

The antimicrobial susceptibility of silver nano particles was evaluated using the antibacterial activity of Ag nano particles for inactivating E. coli O157:H7 (E. coli). The bacteria concentration was determined by the standard surface plating-count methods. Briefly, E. coli was enumerated by surface plating $0.1 \mathrm{~mL}$ dilutions on MacConkey sorbitol agar (Remel) and incubating the plates at $37{ }^{\circ} \mathrm{C}$ for $18-24 \mathrm{~h}$. Then the colonies on the agar plate were counted, a $0.5 \mathrm{~mL}$ of the inoculum containing $1 \times 10^{6}$ cells of $\mathrm{E}$. coli was dropped in a round area (approximately $10 \mathrm{~mm}$ in diameter) at $20{ }^{\circ} \mathrm{C}$. After $5 \mathrm{~min}$, the sample was put into a plastic tube prefilled with $10 \mathrm{~mL}$ of phosphate buffer solution and shaken for $2 \mathrm{~min}$ to wash the bacteria off the substrate. The sample was washed for three times with $1.0 \mathrm{~mL}$ of water and then used for microbial tests to determine the number of viable E. coli cells on the sample. In case of there was no growth of bacteria on the plate, the sample is successful at testing.

\section{Results and Discussions}

\subsection{Formation and characterization of silver nano particles and its properties}

Silver nano particles were synthesized according to the method described in the previous section, UV-visible spectroscopy is one of the most widely used techniques for structural characterization of silver nano particles. The absorption spectrum (Fig. 1) showed a surface Plasmon absorption band with a maximum of $384 \mathrm{~nm}$ indicating the presence of spherical or roughly spherical Ag nano particles[13].

Also, TEM imaging confirmed this; the images show agglomerates of small grains and some dispersed nano particles. The TEM image of the silver synthesized is represented in Fig.2 and indicates well dispersed particles which are more or less spherical, and also shows the presence of faceted particles. The average size of these particles is approximately $30 \mathrm{~nm}$.

The particle size histograms of silver particles (Fig.2) show that the particles range in size from 20 to $80 \mathrm{~nm}$. The corresponding High Energy Electron Diffraction (HEED) pattern of silver particles that shown on the (right-hand in Fig.2) When the electron diffraction is carried out on a limited number of crystals one observes only some spots of diffraction distributed on concentric circles. The rings patterns with plane distances are consistent with the plane families $\{111\},\{200\},\{220\},\{222\}$ and $\{311\}$ of pure face-centred cubic (fcc) silver structure. 


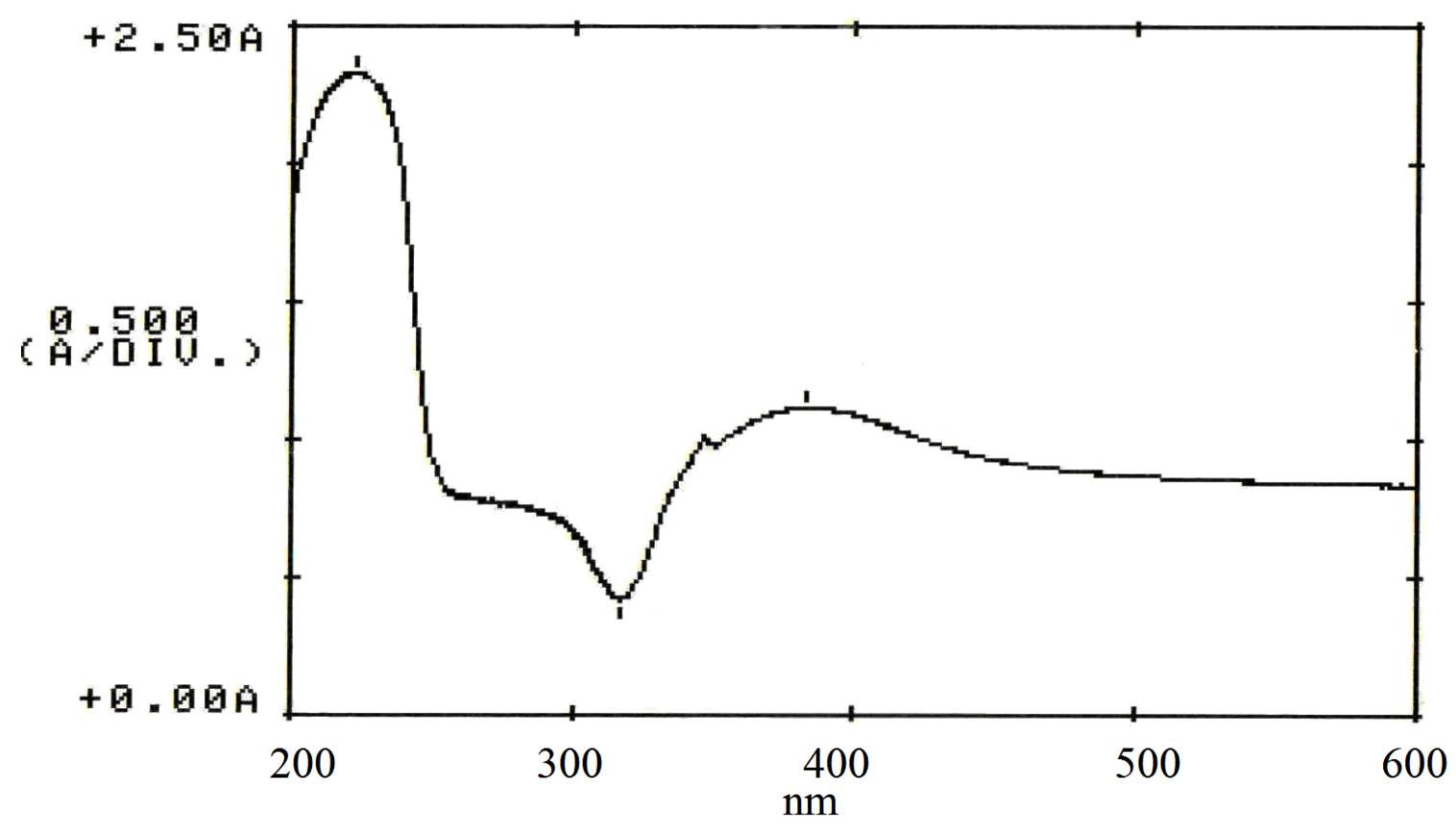

Fig.1. UV-Vis absorption spectrum of silver nano particles

The elemental analysis of the silver nanoparticles was performed using the EDX on the SEM. As shown from Fig. 3 (EDX spectrum) peaks around $2.90 \mathrm{keV}, 3.20 \mathrm{keV}$ and $3.40 \mathrm{keV}$ are obtained corresponding to the binding energies of Ag. No peaks of other impurity have been detected indicating that the prepared sample is pure silver nanoparticles.

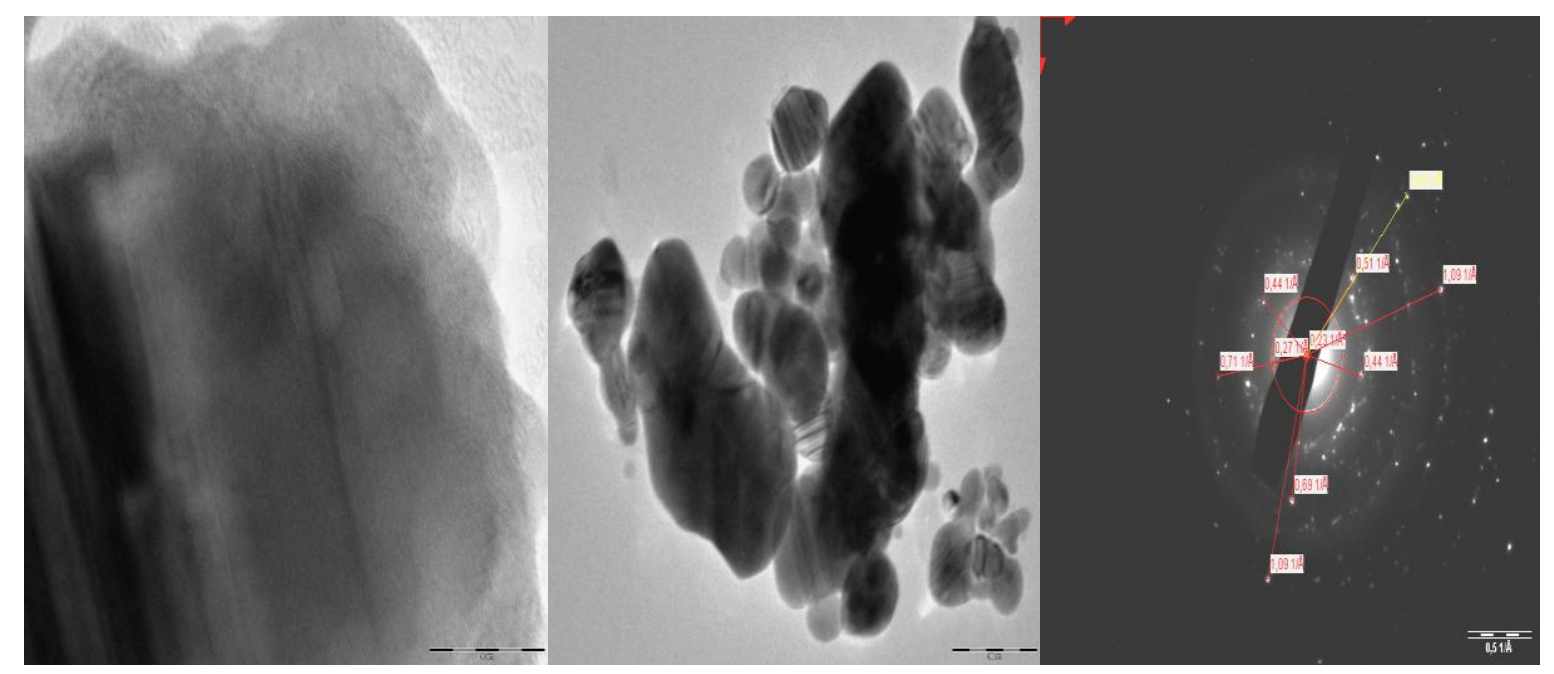

Fig.2. TEM and HEED images of silver nano particles synthesized 


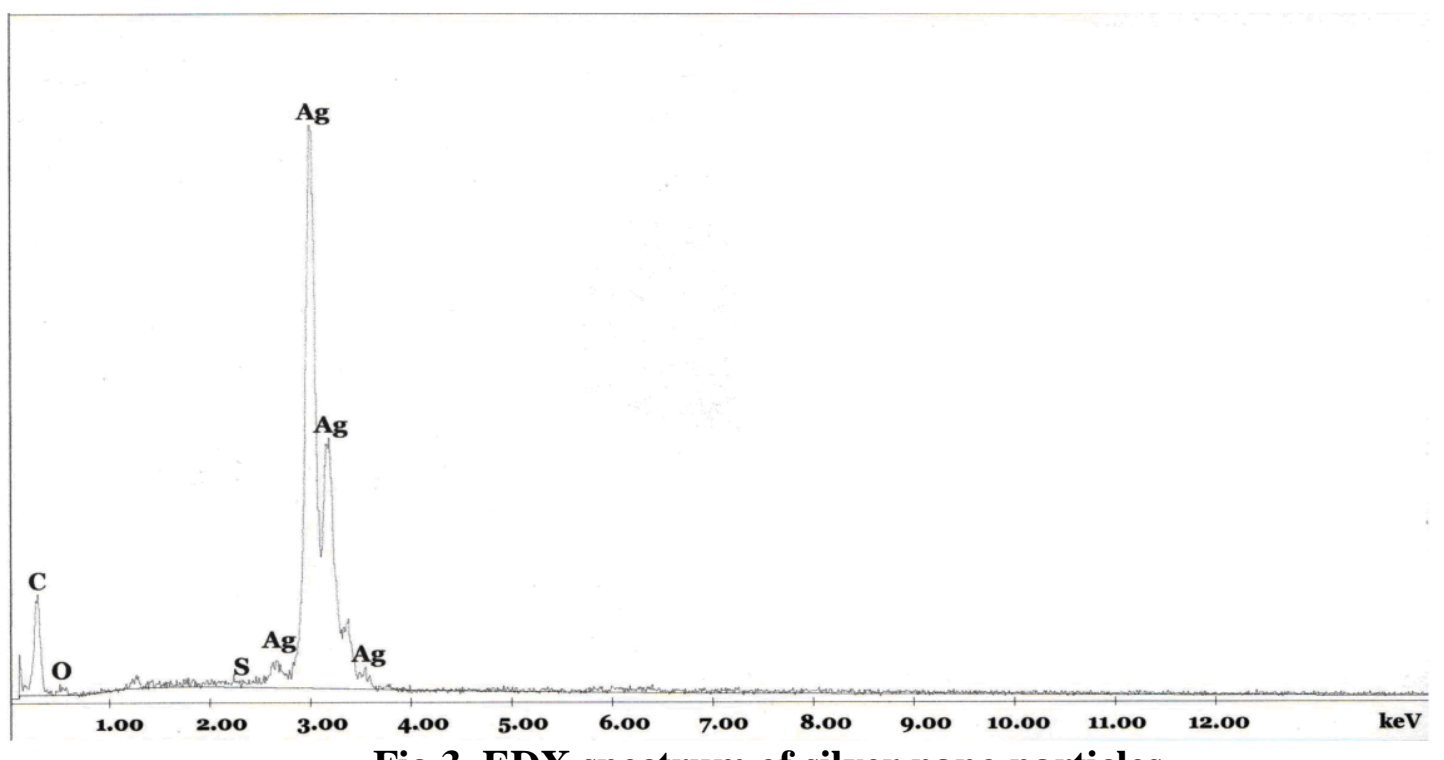

Fig.3. EDX spectrum of silver nano particles

Fig. 4 shows the XRD pattern of powder silver nano particles. The presence of peaks at $2 \theta$ values $38.1^{\circ}, 44.09^{\circ}, 64.36^{\circ}, 77.29^{\circ}$, and $81.31^{\circ}$ corresponds to (111), (200), (220), (222), and (311) planes of silver, respectively, that confirmed as a reference [14]. Thus, the XRD spectrum confirmed the crystalline structure of silver nano particles is a faced centered cube (fcc) [16]. No peaks of other impurity crystalline phases have been detected. All the peaks in XRD pattern can be readily indexed to a face-centered cubic structure of silver.

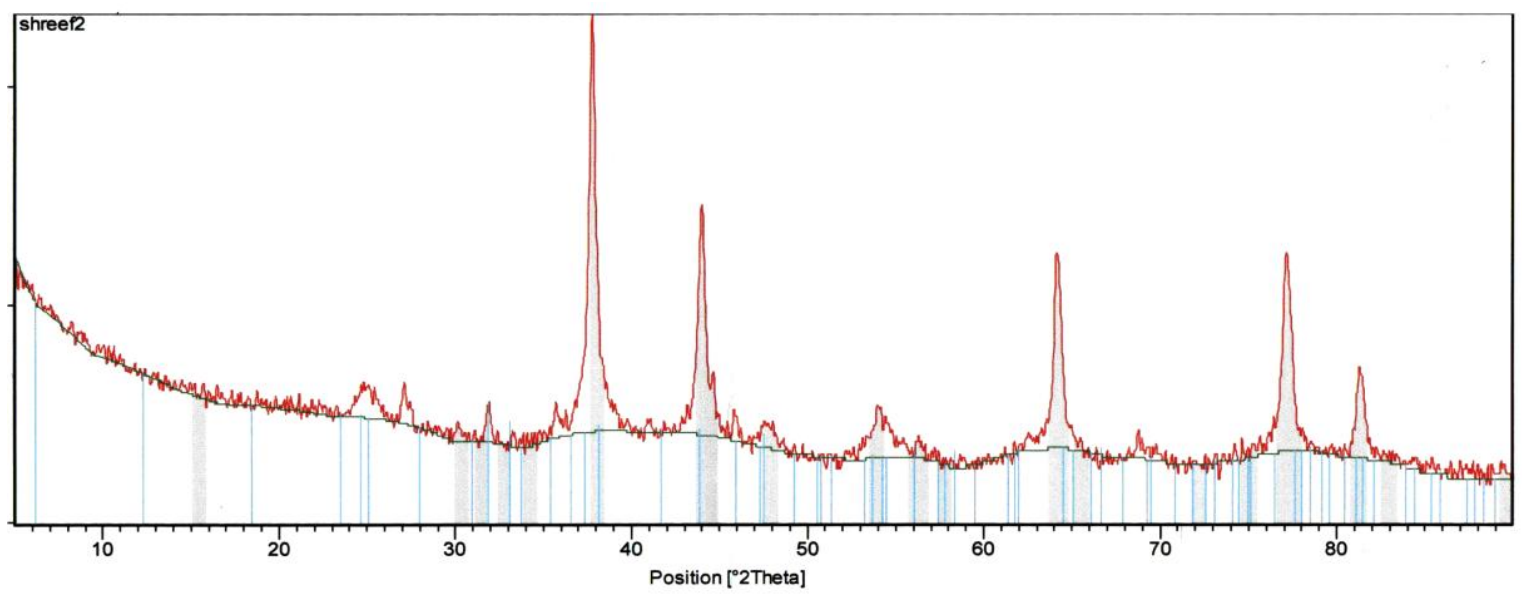

Fig.4. XRD pattern of silver nano particles

\subsection{Effect of silver nano particles and its antibacterial activity}

Fig. 5 shows plates to which a bacterial suspension approximately 106 colonies forming unit per $\mathrm{ml}(\mathrm{CFU}) / \mathrm{ml})$ was applied. The presence of nanoparticles at a certain level inhibited bacterial growth by more than $90 \%$.It is necessary to determine the minimum inhibitory concentration (MIC) of each sample which is $6.82 \mu \mathrm{g} / \mathrm{mL}$.

Antimicrobial activities of the synthesized silver colloidal sols were assessed using the standard dilution micro method, determining the MIC leading to inhibition of bacterial growth (National Committee for Clinical Laboratory Standards, ES1644/1997). 


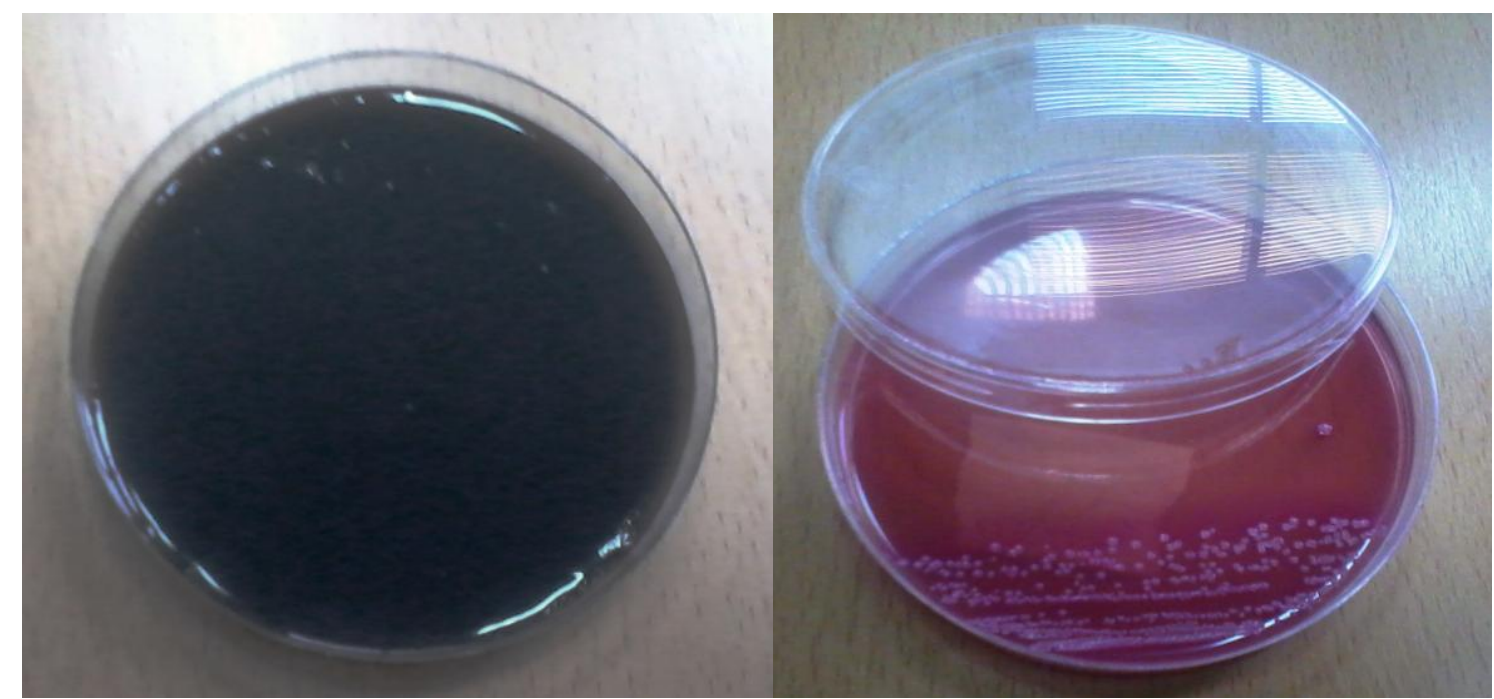

\section{Media of E-Coli O-157 H7 treated with $\mathrm{Ag}(\mathrm{AgNO} 3+\mathrm{NaBH} 4)$}

Media of E-Coli O-157 H7 Without treatment

Fig.5. Appearance of inhibitory zones with Escherichia coli

\section{Conclusion}

In summary, silver nanoparticles with mean diameters of $30 \mathrm{~nm}$ were synthesized using sodium borohydride and citrate of sodium as a reducing agent. The nanoparticles were characterized by UV-Vis, TEM, EDX and XRD. UV-Vis spectra show the characteristic plasmon absorption peak for the silver nanoparticles ranging from 382 to $386 \mathrm{~nm}$. The energy-dispersive spectroscopy (EDX) of the nanoparticles dispersion confirmed the presence of elemental silver signal no peaks of other impurity were detected. High energy electron diffraction (HEED) confirmed that formation of face-centered-cubic silver nanoparticles. Additionally, the antibacterial activity of the nano particle dispersion was measured by standard surface plating-count method.

The results of this study clearly demonstrated that the colloidal silver nanoparticles inhibited the growth and multiplication of the tested bacteria, including highly multiresistant bacteria such as Escherichia coli. Such high antibacterial activity was observed at very low concentrations of silver below $6.82 \mu \mathrm{g} / \mathrm{mL}$.

\section{References}

[1] M. Bron, D. Teschner, A. Knop-Gericke, F. Jentoft, J. Kroehnert, J. Hohmeyer, C. Volckmar, B. Steinhauer, R. Schlogl, P. Claus, Phys. Chem., Romania,2009 .

[2] Mazur M. Electrochemistry Communications 6, USA, 2004.

[3] Pal A., Shah S., Devi S. Colloids and Surfaces A 302,USA, 2007.

[4] Maribel G. Guzmn, Jean Dille, Stephan Godet, World Academy of Science, Engineering and Technology 43,USA, 2008.

[5] Pal S., Kyung Y., Myong Song J. Applied and Environmental Microbiology,China, (2007) . 
[6] Pacios R., Marcilla R., Pozo-Gonzalo C., Pomposo J.A., Grande H., Aizpurua J., Mecerreyes D. J.Nanosci.Nanotechnology, Romania,2007.

[7] Chou,W.L., Yu,D.G., Yang,M.C. PolymER Advanced .Technology,China, 2005.

[8] Shahverdi A.R., Fakhimi A., Shahverdi H.R., Minaian M.S. Nonomedicine,India, 2007.

[9] Kumar A., Joshi H., Pasricha R., Mandale A.B., Sastry M., Journal of Colloid and Interface Science 264,USA,2003.

[10] Li D.G., Chen S.H., Zhao S.Y., Hou X.M.,Ma H.Y.,Yang X.G.,Thin Solid Films,USA, 2004

[11] Performance standards for antimicrobial susceptibility testing $12^{\text {th }}$ informational supplement, Pennsylvania, USA, 2003.

[12] Wilson R., Lynn G., Milosavljevic B., Meisel D., Applied Microbiology, USA, 2007.

[13] Maribel G. Guzmán, Jean Dille, Stephan Godet,Synthesis of silver nanoparticles by chemical reduction method and their antibacterial activity, World Academy of Science, Engineering and Technology 43,USA, 2008.

[14] Mohd Abdul Majeed Khan, Sushil Kumar, Maqusood Ahamed, Salman A Alrokayan and Mohammad Saleh AlSalhi, Structural and thermal studies of silver nanoparticles and electrical transport study of their thin films, Nanoscale Research Letters, Saudi Arabia, 2011. 